\title{
The *1244 A>G polymorphism of MyD88 (rs7744) is closely associated with susceptibility to ulcerative colitis
}

\author{
KAZUHIRO MATSUNAGA ${ }^{1}$, TOMOMITSU TAHARA ${ }^{2}$, HISAKAZU SHIROEDA ${ }^{1}$, TOSHIMI OTSUKA ${ }^{1}$, \\ MASAKATSU NAKAMURA ${ }^{1}$, TAKEO SHIMASAKI ${ }^{1}$, NOBUYUKI TOSHIKUNI ${ }^{1}$, NATSUKO KAWADA ${ }^{1}$, \\ TOMOYUKI SHIBATA $^{2}$ and TOMIYASU ARISAWA ${ }^{1}$ \\ ${ }^{1}$ Department of Gastroenterology, Kanazawa Medical University, Uchinada-machi, Ishikawa 920-0293; \\ ${ }^{2}$ Department of Gatroenterology, Fujita Health University, Kutsukake-cho, Toyoake 470-1192, Japan
}

Received July 19, 2013; Accepted October 29, 2013

DOI: $10.3892 / \mathrm{mmr} .2013 .1769$

\begin{abstract}
Toll-like receptor activation intitially recruits the myeloid differentiation primary response gene (88) (MyD88) protein. A polymorphism *1244 $\mathrm{A}>\mathrm{G}$ (rs7744) in the 3'-untranslated region of $M y D 88$ has been identified. In the present study, the association of this polymorphism with ulcerative colitis (UC) was investigated. The population studied comprised 922 individuals, including patients with UC (UC cases) and without (controls). Genotyping of rs7744 was performed by PCR single-strand conformation polymorphism and the rs7744 $\mathrm{G}$ allele frequencies in the controls and UC cases were 32.8 and $43.5 \%$, respectively $(\mathrm{P}<0.0001)$. The results showed that the genotype frequency of the AA homozygote was significantly lower and that of the GG homozygote was significantly higher in the UC cases compared with those in the controls ( $\mathrm{P}=0.0012$ for both groups). The rs 7744 minor allele variants were significantly associated with susceptibility to UC as indicated by dominant and recessive genetic models. The minor allele variants were associated with an increased risk for UC in the male individuals but not the female individuals. The rs 7744 was also associated with a non-continuous phenotype of UC and steroid unused/independent UC. This minor allele homozygote was associated with the disease severity of UC, hospitalization and response to steroid treatment. The results of the present study provided evidence that MyD88 polymorphism rs7744 was significantly associated with the development of UC and that this polymorphism may be associated with the response to treatment therapies for UC.
\end{abstract}

\section{Introduction}

Ulcerative colitis (UC) is precipitated by a complex interaction of environmental, genetic and immunoregulatory

Correspondence to: Professor Tomiyasu Arisawa, Department of Gastroenterology, Kanazawa Medical University, 1-1, Daigaku, Uchinada-machi, Ishikawa 920-0293, Japan

E-mail: tarisawa@kanazawa-med.ac.jp

Key words: MyD88, genetic polymorphism, ulcerative colitis factors $(1,2)$. Owing to the westernization of lifestyle and dietary habits, the number of UC patients has increased considerably in some Asian countries, including Japan and China (3). UC has an impact on the colon and rectum and usually involves the innermost lining mucosa, appearing as continuous areas of inflammation, with no segments of normal mucosa (4). Although the pathogenesis of UC is only partially understood, previous studies have indicated the significant role of the innate immune response in the pathogenesis of UC $(5,6)$. In addition, a number of genes are associated with UC itself (7-10).

The biology of the innate immunity receptors is crucial in the host response to the environment. Toll-like receptors (TLRs) play a significant role in the gut innate immunity and are involved in human inflammatory bowel diseases, including UC (11). TLR activation initially recruits the myeloid differentiation primary response gene (88) (MyD88) protein, a common adaptor protein that is fundamental in the innate immune response activation (12). MyD88 has an intermediate domain that is crucial in TLR signaling as it interacts with interleukin-1 receptor-associated kinase. It has been reported that a polymorphism in the 3'-untranslated region (UTR) of MyD88 (rs7744, *1244 A>G) is associated with susceptibility to Buerger disease in Japanese individuals (13). $M y D 88$ is located at chromosome $3 \mathrm{p} 22$ and its length is $\sim 4.5 \mathrm{kbp}$. There is no other polymorphism excluding rs 7744 , with $\mathrm{P}>0.01$ for Hardy-Weinberg equilibrium and $\mathrm{P}>0.05$ for the minor allele frequency, within $10 \mathrm{kbp}$ around MyD88 and no polymorphism in LD with rs7744 is observed within $20 \mathrm{kbp}$ in the haplotype map of Japanese individuals (HapMap-JPT). In addition, there are binding sites of several microRNAs near *1244 A>G, including miR-29b-2-5p, miR-150-3p and miR-1236. Polymorphisms near the miRNA binding site in mRNA 3'-UTR may affect the binding of miRNAs to mRNA (14). Based on these results, we hypothesized that rs7744 has an impact on the MyD88-dependent pathway of the innate immune response via TLRs. It has been indicated that the TLR-4-MyD88 pathway may play a significant role on the pathogenesis of UC (15).

In the present study, the association of the MyD88 polymorphism rs7744 (*1244 A>G) with its susceptibility to UC was investigated. 
Table I. Characteristics of the subjects and allelic frequency.

\begin{tabular}{lccc}
\hline Characteristics & Controls & UC cases & P-value \\
\hline $\begin{array}{l}\text { Number of samples } \\
\text { Mean age } \pm \text { SD }\end{array}$ & 722 & 200 & $\mathrm{P}<0.0001$ \\
(age of onset) & $54.5 \pm 16.4$ & $40.0 \pm 13.6$ & $\mathrm{NS}$ \\
Male:female & $424: 298$ & $113: 87$ & $\mathrm{P}=0.0012$ \\
rs7744 A $>$ G & & & \\
AA & 320 & 100 & $\mathrm{P}=0.0012$ \\
AG & 331 & 37 & $\mathrm{P}<0.0001$ \\
GG & 71 & $43.5 \%$ & \\
G allele freqency & $32.8 \%$ & & \\
\hline
\end{tabular}

P-value, controls vs. UC cases. NS, not significant; UC, ulcerative colitis.

\section{Materials and methods}

Clinical samples. The studied population comprised 922 subjects, including patients with UC (UC cases, $n=200$ ), who were enrolled at the Fujita Health University Hospital or Kanazawa Medical University Hospital (Kutsukake-cho or Uchinada-machi, Japan), and subjects without UC (controls, $\mathrm{n}=722$ ). The diagnosis of UC was based on standard clinical, endoscopic, radiological and histological criteria (16). The control subjects had no lower abdominal symptoms, diarrhea or hematochezia. Genomic DNA was isolated from peripheral blood using a FlexiGene DNA kit (QIAGEN GmbH, Hilden, Germany).

The Ethics Committees of Fujita Health University and Kanazawa Medical University approved the protocol, and written informed consent was obtained from the participating subjects.

Sample size. First, we assessed the genotype of 200 UC cases. Based on the frequency of the rs 7744 minor allele in the UC cases $(43.5 \%)$ in the present study an assumption was made that a $20 \%$ decrease in the prevalence of an allelic frequency would be of clinical relevance. Assuming $\alpha=0.05$ and power $=0.80$, at least $200 \mathrm{UC}$ cases and 400 controls would be sufficient to identify a clinically relevant difference. Accordingly, 750 subjects without UC would be of sufficiently clinical relevance for the study. A total of 722 of 750 subjects whose genotype was clearly determined were included as controls.

Classification. According to their clinical courses, the UC cases were classified into continuous and non-continuous disease (relapsing and only one episode) (16). UC patients were also classified as total colitis or non-total colitis (left sided, distal colitis and proctitis) according to the location and extension of the inflammatory lesions judged by the endoscopic findings. The cases that need continuous intravenous or oral steroid therapy were identified as steroid-dependent, and those that had one onset over 6 months or 2 onsets within one year were defined as refractory cases.

Genotyping of polymorphisms. Polymorphism was genotyped by the PCR single-strand conformation polymorphism (SSCP) method as reported previously $(17,18)$. The primers used to detect rs7744 A>G were: MyD88 forward, 5'-cettttctettgtgt ccctactcattg-3' and reverse, 5'-cagctctcttcctctctctgtgcttc-3'. A PCR reaction was carried out in a volume of $20 \mu \mathrm{l}$ containing $0.1 \mu \mathrm{g}$ genomic DNA. The DNA was denatured at $95^{\circ} \mathrm{C}$ for $3 \mathrm{~min}$, followed by 35 cycles at $95^{\circ} \mathrm{C}$ for $30 \mathrm{sec}, 52^{\circ} \mathrm{C}$ for $40 \mathrm{sec}$ and $72^{\circ} \mathrm{C}$ for $45 \mathrm{sec}$, with a final extension at $72^{\circ} \mathrm{C}$ for $5 \mathrm{~min}$. Thereafter, $2 \mu \mathrm{l}$ PCR product was denatured with $10 \mu \mathrm{l}$ formamide (Sigma-Aldrich Co., St. Louis, MO, USA) at $90^{\circ} \mathrm{C}$ for $5 \mathrm{~min}$. SSCP was carried out at $18^{\circ} \mathrm{C}$ using a GenePhor DNA separation system with GeneGel Excel 12.5/24 (GE Healthcare Japan, Tokyo, Japan), after which the denatured single-strand DNA bands were detected using a DNA silver staining kit (Amersham Biosciences Corp.).

Statistical analysis. The data of the age was expressed as the mean $\pm \mathrm{SD}$. The mean ages between the two groups were compared by the Student's t-test. Allelic and genotype frequencies were calculated by direct counting. The allele counts and distribution of genotype were compared between the cases and the controls by a $2 \times 2$ table using Fisher's exact test. Furthermore, the strength of the association between allele frequencies and the disease was assessed by calculating the odds ratio (OR) and 95\% confidence intervals (CIs) by logistic multivariate regression analysis. For all the analyses, $\mathrm{P}<0.05$ was used to indicate a statistically significant difference.

\section{Results}

Characteristics of subjects and the frequencies of genotypes. As shown in Fig. 1, single-stranded DNAs were clearly separated by SSCP. The allele frequency of $M y D 88$ rs7744 in the controls was in Hardy-Weinberg equilibrium $(\mathrm{P}=0.31)$. The mean age in the controls was significantly higher compared with that in the UC cases (Table I). The genotype frequency of the rs7744 AA homozygote was significantly lower and that of the GG homozygote was significantly higher in the UC cases compared with the controls $(\mathrm{P}=0.0012$ and 0.0012 , respectively). The minor allele frequency of rs7744 was 32.8 and $43.5 \%$ in the controls and UC cases, respectively $(\mathrm{P}<0.0001)$. 
Table II. Association between rs7744 and UC.

\begin{tabular}{|c|c|c|c|c|c|c|}
\hline \multirow[t]{2}{*}{ Variables } & \multicolumn{3}{|c|}{ Genotype, $\mathrm{n}$} & \multirow{2}{*}{$\frac{\mathrm{AG}+\mathrm{GG} \text { vs. AA }}{\mathrm{OR}(95 \% \mathrm{CI})}$} & \multirow{2}{*}{$\frac{\mathrm{GG} \text { vs. AA + AG }}{\text { OR }(95 \% \mathrm{CI})}$} & \multirow{2}{*}{$\frac{\text { No. of G allele }{ }^{\mathrm{a}}}{\text { OR }(95 \% \mathrm{CI})}$} \\
\hline & $\mathrm{AA}$ & AG & GG & & & \\
\hline \multicolumn{7}{|l|}{ Overall } \\
\hline Controls (722) & 320 & 331 & 71 & Reference & Reference & Reference \\
\hline UC cases (200) & 63 & 100 & 37 & $1.64(1.15-2.34)^{\mathrm{b}}$ & $1.87(1.17-3.00)^{\mathrm{c}}$ & $1.52(1.18-1.95)^{\mathrm{d}}$ \\
\hline \multicolumn{7}{|l|}{ Male } \\
\hline Controls (424) & 191 & 198 & 35 & Reference & Reference & Reference \\
\hline UC cases (113) & 33 & 61 & 19 & $1.90(1.19-3.04)^{\mathrm{e}}$ & $1.93(1.01-3.68)^{\mathrm{f}}$ & $1.66(1.19-2.33)^{\mathrm{g}}$ \\
\hline \multicolumn{7}{|l|}{ Female } \\
\hline Controls (298) & 129 & 133 & 36 & Reference & Reference & Reference \\
\hline UC cases (87) & 30 & 39 & 18 & $1.35(0.78-2.34)$ & $1.83(0.90-3.72)$ & $1.37(0.931-2.00)$ \\
\hline
\end{tabular}

${ }^{\mathrm{a}}$ Analysis using the number of $\mathrm{G}$ allele as a co-variate. Overall, by logistic regression analysis following adjustment for age and gender. P-values: ${ }^{\mathrm{b}} 0.0063,{ }^{\mathrm{c}} 0.0094$ and ${ }^{\mathrm{d}} 0.0010$. Male and female, by logistic regression analysis following adjustment for age. $\mathrm{P}$-values: ${ }^{\mathrm{e}} 0.0071,{ }^{\mathrm{f}} 0.045$ and ${ }^{\mathrm{g}} 0.0029$. UC, ulcerative colitis.

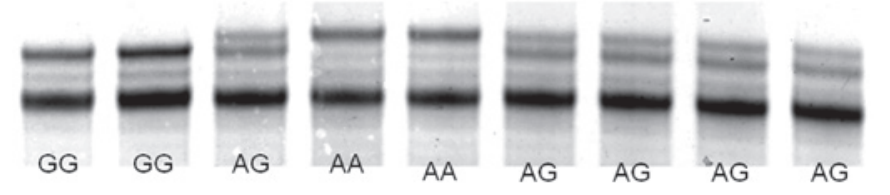

Figure 1. The images of PCR-SSCP using clinical samples. Single strand DNAs were clearly separated by SSCP. SSCP, single-strand conformation polymorphism.

Association between the rs7744 and UC. The rs7744 minor allele was significantly associated with an increased risk for UC using the dominant and recessive genetic models (OR, 1.64; 95\% CIs, 1.15-2.34; $\mathrm{P}=0.0063$ and $\mathrm{OR}, 1.87 ; 95 \%$ CIs, 1.17-3.00 and $\mathrm{P}=0.0094$, respectively, Table II). In the analysis using the number of minor alleles as a co-variate, the significant association of the rs7744 minor allele was also observed (OR, 1.52; 95\% CIs, 1.18-1.95 and $\mathrm{P}=0.0010)$. This association was observed in the male subjects in the same manner (dominant genetic model: OR, 1.90; 95\% CIs, 1.19-3.04 and $\mathrm{P}=0.0071$, recessive genetic model: $\mathrm{OR}, 1.93$; 95\% CIs, $1.01-3.68$ and $\mathrm{P}=0.045$, and the number of minor allele: OR, 1.66; 95\% CIs, $1.19-2.33$ and $\mathrm{P}=0.0029)$, but was not observed in the female individuals.

Association between the rs7744 and phenotypes of UC. The rs7744 polymorphism was associated with UC cases with onset after 31 years of age by all the genetic models (Table III). In addition, this polymorphism was significantly associated with non-continuous disease and non-total colitis by all the genetic models. In the recessive genetic model, the rs7744 polymorphism was associated with non-total and total colitis.On the other hand, this association of rs7744 appeared not to have a difference because of disease severity or hospitalization. Moreover, the rs7744 polymorphism was significantly associated with steroid-dependent or -unused cases in all the genetic models, whereas this polymorphism was associated with steroid-dependent cases only in the recessive genetic model.

\section{Discussion}

In the present study, the association between polymorphism rs7744 (*1244 A>G) in the 3'-UTR of MyD88 and the risk for development of UC was evaluated. The rs7744 minor allele variant was significantly associated with an increased risk for UC, in particular in the male subjects. In addition, this polymorphism was associated with cases with an older age of onset, non-continuous disease and steroid-independent or -unused cases in the dominant and recessive genetic models. On the other hand, the rs7744 GA + GG genotype was associated with cases without hospitalization and cases with a UCDAI score $<8$, whereas the GG homozygote was associated with cases with hospitalization, with a UDCAI score $>9$ and steroid-dependent cases. These results indicate that the rs7744 minor allele variant may be associated with the development of UC and the minor allele homozygote with the severity of UC. In the present study, sample selection may have affected the outcome as the controls included unhealthy individuals who presented at hospital for treatment for problems excluding diarrhea, bloody feces and lower abdominal discomfort. Although a comparison of allele frequencies between the UC cases and controls have an adequately statistical power $(1-\beta=0.971)$, the effect of type II error cannot be excluded by relatively small sample sizes in other comparisons. Another limitation of the present study was that the mean age was different among the controls and UC cases. Therefore, an analyis was performed using a logistic multivariate regression analysis following adjustment for age. However, it appears that this is not an obstacle to the analysis, as UC develops at a relatively young age.

It is well known that a major inducer of the inflammation response to Gram-negative bacteria is lipopolysaccharide, derived from the outer envelopes of these microorganisms (19). Lipopolysaccharide signaling is mainly mediated through the 
Table III. Association between rs7744 and the phenotype of UC.

\begin{tabular}{|c|c|c|c|c|c|c|}
\hline \multirow[b]{2}{*}{ Variables } & \multicolumn{3}{|c|}{ Genotype, n } & \multirow{2}{*}{$\frac{\mathrm{AG}+\mathrm{GG} \text { vs. AA }}{\mathrm{OR}(95 \% \mathrm{CI})}$} & \multirow{2}{*}{$\frac{\mathrm{GG} \text { vs. } \mathrm{AA}+\mathrm{AG}}{\mathrm{OR}(95 \% \mathrm{CI})}$} & \multirow{2}{*}{$\begin{array}{l}\text { No. of G allele } \\
\text { OR }(95 \% \mathrm{CI})\end{array}$} \\
\hline & AA & $\mathrm{AG}$ & GG & & & \\
\hline Controls (722) & 320 & 331 & 71 & Reference & Reference & Reference \\
\hline \multicolumn{7}{|l|}{ Age of onset } \\
\hline$\leq 30(92)$ & 33 & 42 & 17 & $1.19(0.717-1.98)$ & $1.51(0.766-2.96)$ & $1.22(0.852-1.74)$ \\
\hline$\geq 31(93)$ & 27 & 49 & 17 & $1.90(1.18-3.05)^{\mathrm{a}}$ & $2.03(1.13-3.66)^{\mathrm{b}}$ & $1.67(1.21-2.31)^{\mathrm{c}}$ \\
\hline \multicolumn{7}{|l|}{ Clinical type } \\
\hline Not continuous (111) & 31 & 58 & 22 & $1.91(1.21-3.02)^{\mathrm{d}}$ & $2.02(1.15-3.54)^{\mathrm{e}}$ & $1.67(1.23-2.28)^{\mathrm{f}}$ \\
\hline Continuous (82) & 31 & 38 & 13 & $1.23(0.754-2.00)$ & $1.58(0.807-3.11)$ & $1.25(0.881-1.79)$ \\
\hline \multicolumn{7}{|l|}{ Extension } \\
\hline Non-total colitis (108) & 31 & 57 & 20 & $1.82(1.15-2.88)^{\mathrm{g}}$ & $1.89(1.06-3.38)^{\mathrm{h}}$ & $1.61(1.17-2.20)^{\mathrm{i}}$ \\
\hline Total colitis (89) & 29 & 43 & 17 & $1.55(0.955-2.52)$ & $1.92(1.04-3.56)^{\mathrm{j}}$ & $1.49(1.06-2.09)^{\mathrm{k}}$ \\
\hline \multicolumn{7}{|l|}{ Max. UCDAI score } \\
\hline$\leq 8(105)$ & 32 & 56 & 17 & $1.74(1.11-2.74)^{1}$ & $1.68(0.927-3.06)$ & $1.52(1.11-2.09)^{\mathrm{m}}$ \\
\hline$\geq 9$ (88) & 30 & 40 & 18 & $1.37(0.838-2.25)$ & $2.01(1.07-3.75)^{\mathrm{n}}$ & $1.42(1.01-2.01)^{\mathrm{o}}$ \\
\hline \multicolumn{7}{|l|}{ Hospitalization } \\
\hline None (121) & 35 & 67 & 19 & $1.87(1.21-2.88)^{\mathrm{p}}$ & $1.63(0.919-2.90)$ & $1.57(1.16-2.12)^{\mathrm{q}}$ \\
\hline More than once (69) & 26 & 29 & 14 & $1.19(0.696-2.03)$ & $2.05(1.04-4.04)^{\mathrm{r}}$ & $1.33(0.912-1.95)$ \\
\hline \multicolumn{7}{|l|}{ Response to treatment } \\
\hline Steroid-dependent (42) & 17 & 14 & 11 & $1.03(0.532-1.98)$ & $2.71(1.25-5.85)^{\mathrm{s}}$ & $1.37(0.864-2.18)$ \\
\hline Steroid-refractory (56) & 18 & 27 & 11 & $1.46(0.796-2.67)$ & $1.88(0.886-3.97)$ & $1.44(0.948-2.19)$ \\
\hline $\begin{array}{l}\text { Steroid independent or } \\
\text { unused }(155)\end{array}$ & 41 & 70 & 24 & $1.76(1.17-2.66)^{\mathrm{t}}$ & $1.85(1.08-3.16)^{\mathrm{u}}$ & $1.57(1.18-2.09)^{\mathrm{v}}$ \\
\hline
\end{tabular}

By logistic regression analysis following adjustment for age and gender. P-value: ${ }^{\mathrm{a}} 0.0081 ;{ }^{\mathrm{b}} 0.018 ;{ }^{\mathrm{c}} 0.0018 ;{ }^{\mathrm{d}} 0.0054 ;{ }^{\mathrm{e}} 0.014 ;{ }^{\mathrm{f}} 0.0012 ;{ }^{\mathrm{g}} 0.011$; ${ }^{\mathrm{h}} 0.031 ;{ }^{\mathrm{i}} 0.0033 ;{ }^{\mathrm{j}} 0.038 ;{ }^{\mathrm{k}} 0.020 ;{ }^{1} 0.016 ;{ }^{\mathrm{m}} 0.0087 ;{ }^{\mathrm{n}} 0.029 ;{ }^{\circ} 0.045 ;{ }^{\mathrm{p}} 0.0047 ;{ }^{\mathrm{q}} 0.0035 ;{ }^{\mathrm{r}} 0.039 ;{ }^{\mathrm{s}} 0.011 ;{ }^{\mathrm{t}} 0.0068 ;{ }^{\mathrm{u}} 0.024$ and ${ }^{\mathrm{v}} 0.0020$.

cell surface TLRs, which have been shown to be extremely important to gut homeostasis during host-microbial interactions $(20,21)$. TLR-4 plays a significant role in gut innate immunity, protection and is involved in human inflammatory bowel diseases (IBDs), including UC $(22,23)$. Cantó et al reported that a marked increase of TNF- $\alpha$ response to TLR2 ligands correlated with a higher TLR2 expression in Crohn's disease and UC patients, indicating that an abnormal mechanism may provide an excess of inflammatory mediators during the active phases of IBDs (24). This TLR signaling acts through a downstream regulator, MyD88, which initiates a signal transduction cascade leading to the induction of NF- $\kappa \mathrm{B}$ (12). Although TLRs signal transmit through the MyD88-dependent or -independent pathway, previous studies have indicated a significant role of the TLR-MyD88 pathway on IBD $(15,25)$. Aoyagi et al have reported that mRNA levels of MyD88, TLR-4 and NF- $\kappa$ B p65 are significantly increased in colonic mucosa of UC patients (26). It has also been reported that the Myd88 protein level is increased in the colonic mucosa of non-treated UC and this increase is suppressed by azathioprine treatment (15). Therefore, MyD88 is considered one of the key molecules in the pathogenesis of UC and an overexpression of MyD88 may promote the development of UC.

MyD 88 is located on chromosome $3 \mathrm{p} 22$, a position that is not included in UC susceptible loci (27). However, rs7744, which is the only polymorphism in $M y D 88$, may be associated with the susceptibility or pathogenesis of UC, if the expression and function of MyD88 undergo certain effects by the polymorphisms in $M y D 88$. To the best of our knowledge, there is only one study regarding the investigation of an association between $M y D 88$ polymorphism and human disorders. Although Chen et al have reported that rs7744 is associated with Buerger disease in Japanese individuals (131 cases and 270 controls) (13), the function of rs7744 has not been identified. In addition, there is no evidence regarding the function of rs7744. However, there may be a possibility of overexpressing the MyD88 protein in the rs7744 minor allele variants, considering overexpression of mRNA and protein levels of MyD88 in UC patients $(15,26)$. There are binding sites of miR-150-3p and miR-1236 of $100 \mathrm{bp}$ around rs7744. miRNAs bind to the RNA-induced silencing complex, making it non-symmetrical which then binds to the target mRNA to regulate its expression (28). In the rs7744 minor allele variants, cleavage of mRNA or repression of protein synthesis by miRNAs may not be well-regulated.

In the present study, $M y D 88$ rs7744 was associated with non-continuous phenotypes of UC and steroid unused/independent UC. In addition, this minor allele homozygote was associated with the disease severity of UC, hospitalization and response to steroid treatment. Potter et al have reported that 
rs7744 is nominally associated with a response to anti-TNF therapy for rheumatoid arthritis (29). This evidence indicates that rs7744 may be associated with a response to treatment for UC. The reason for this genotype being associated with specific phenotypes or the male cases of UC remains to be determined. UC is a multi-factorial disorder including genetic and environmental factors, and is considered a complex genetic disorder predicted to involve multiple genes of relatively low penetrance (30). In fact, Fisher et al have reported that several regions of the male-specific linkage were identified in the susceptibility to inflammatory bowel disease (31). It may not be surprising that the $M y D 88$ polymorphism is more closely associated with the specific phenotypes of UC. Future studies should be conducted to clarify how the MyD 88 polymorphism affects the susceptibility to UC.

In conclusion, the minor allele variant of rs7744, which is located in $M y D 88$ 3'-UTR, is significantly associated with the susceptibility to UC, in particular in the Japanese male subjects. This polymorphism may also be associated with the response to treatment for $\mathrm{UC}$.

\section{References}

1. Podolsky DK: Inflammatory bowel disease. N Engl J Med 347: 417-429, 2002.

2. Chamaillard M,Philpott D, Girardin SE, et al: Gene-environment interaction modulated by allelic heterogeneity in inflammatory diseases. Proc Natl Acad Sci USA 100: 3455-3460, 2003.

3. Sakamoto N, Kono S, Wakai K, et al; Epidemiology Group of the Research Committee on Inflammatory Bowel Disease in Japan. Dietary risk factors for inflammatory bowel disease: a multicenter case-control study in Japan. Inflamm Bowel Dis 11: 154-163, 2005.

4. Head KA and Jurenka JS: Inflammatory bowel disease part 1. Ulcerative colitis - pathophysiology and conventional and alternative treatment options. Altern Med Rev 8: 247-283, 2003.

5. Lakatos PL, Fischer S,Lakatos L, Gal I and Papp J: Current concept on the pathogenesis of inflammatory bowel disease-crosstalk between genetic and microbial factors: pathogenic bacteria and altered bacterial sensing or changes in mucosal integrity take 'toll'? World J Gastroenterol 12: 1829-1841, 2006.

6. Gersemann M, Wehkamp J and Stange EF: Innate immune dysfunction in inflammatory bowel disease. J Intern Med 271: 421-428, 2012.

7. UK IBD Genetics Consortium, Barrett JC, Lee JC, Lees CW et al: Genomewide association study of ulcerative colitis identifies three new susceptibility loci, including the HNF4A region. Nat Genet 41: 1330-1334, 2009.

8. Silverberg MS, Cho JH, Rioux JD, et al: Ulcerative colitis-risk loci on chromosomes 1p36 and 12q15 found by genome-wide association study. Nat Genet 41: 216-220, 2009.

9. McGovern DP, Gardet A, Törkvist L, et al: Genome-wide association identifies multiple ulcerative colitis susceptibility loci. Nat Genet 42: 332-337, 2010.

10. Franke A, Balschun T, Sina C, et al: Genome-wide association study for ulcerative colitis identifies risk loci at 7q22 and 22q13 (IL17REL). Nat Genet 42: 292-294, 2010.

11. Fukata M and Abreu MT: TLR4 signaling in the intestine in health and disease. Biochem Soc Trans 35: 1473-1478, 2007.
12. Arancibia SA, Béltran CJ, Aguirre IM, et al: Toll-like receptors are key participants in innate immune responses. Biol Res 40: 97-112, 2007.

13. Chen Z, Nakajima T, Inoue Y, et al: A single nucleotide polymorphism in the 3'-untranslated region of MyD88 gene is associated with Buerger disease but not with Takayasu arteritis in Japanese. J Hum Genet 56: 545-547, 2011.

14. Mishra PJ and Bertino JR: MicroRNA polymorphisms: the future of pharmacogenomics, molecular epidemiology and individualized medicine. Pharmacogenomics 10: 399-416, 2009.

15. Siddique I and Khan I: Mechanism of regulation of $\mathrm{Na}-\mathrm{H}$ Exchanger in inflammatory bowel disease: role of TLR-4 signaling mechanism. Dig Dis Sci 56: 1656-1662, 2011.

16. Podolsky DK: Inflammatory bowel disease (2). N Engl J Med 325: 1008-1016, 1991.

17. Arisawa T, Tahara T, Shibata T, et al: A polymorphism of microRNA 27 a genome region is associated with the development of gastric mucosal atrophy in Japanese male subjects. Dig Dis Sci 52: 1691-1697, 2007.

18. Arisawa T, Tahara T, Shiroeda H, et al: NFKB1 polymorphism is associated with age-related gene methylation in Helicobacter pylori-infected subjects. Int J Mol Med 30: 255-262, 2012.

19. Ruemmele FM, Beaulieu JF, Dionne S, et al: Lipopolysaccharide modulation of normal enterocyte turnover by toll-like receptors is mediated by endogenously produced tumour necrosis factor alpha. Gut 51: 842-848, 2002.

20. Boone DL and Ma A: Connecting the dots from Toll-like receptors to innate immune cells and inflammatory bowel disease. J Clin Invest 111: 1284-1286, 2003.

21. Pierik M, Joossens S, Van Steen K, et al: Toll-like receptor-1, -2 , and -6 polymorphisms influence disease extension in inflammatory bowel diseases. Inflamm Bowel Dis 12: 1-8, 2006.

22. Lubbad A, Oriowo MA and Khan I: Curcumin attenuates inflammation through inhibition of TLR-4 receptor in experimental colitis. Mol Cell Biochem 322: 127-135, 2009.

23. Sepúlveda SE, Beltrán CJ, Peralta A, et al: [Inflammatory bowel diseases: an immunological approach]. Rev Med Chil 136: 367-375, 2008 (In Spanish).

24. Cantó E, Ricart E, Monfort D, et al: TNF alpha production to TLR2 ligands in active IBD patients. Clin Immunol 119: 156-165, 2006.

25. Tomita T, Kanai T, Fujii T, et al: MyD88-dependent pathway in $\mathrm{T}$ cells directly modulates the expansion of colitogenic $\mathrm{CD} 4^{+}$ T cells in chronic colitis. J Immunol 180: 5291-5299, 2008.

26. Aoyagi Y, Nagata S, Kudo T, et al: Peroxisome proliferatoractivated receptor $\gamma 2$ mutation may cause a subset of ulcerative colitis. Pediatr Int 52: 729-734, 2010.

27. Hugot JP and Thomas G: Genome-wide scanning in inflammatory bowel diseases. Dig Dis 16: 364-369, 1998.

28. Scott GK, Goga A, Bhaumik D, Berger CE, Sullivan CS and Benz CC: Coordinate suppression of ERBB2 and ERBB3 by enforced expression of micro-RNA miR-125a or miR-125b. J Biol Chem 282:1479-1486, 2007.

29. Potter C, Cordell HJ, Barton A, et al; Biologics in Rheumatoid Arthritis Genetics and Genomics Study Syndicate (BRAGGSS). Association between anti-tumour necrosis factor treatment response and genetic variants within the TLR and NF\{kappa\} B signalling pathways. Ann Rheum Dis 69: 1315-1320, 2010.

30. Cho JH and Brant SR: Genetics and genetic markers in inflammatory bowel disease. Curr Opin Gastroenterol 14: 283-288, 1998.

31. Fisher SA, Hampe J, Macpherson AJ, et al: Sex stratification of an inflammatory bowel disease genome search shows male-specific linkage to the HLA region of chromosome 6. Eur J Hum Genet 10: 259-265, 2002. 